\title{
Environment-friendly synthesis of long chain semiaromatic polyamides
}

\author{
W.-Z. Wang, Y.-H. Zhang* \\ College of Material Science and Engineering, South China University of Technology, 381 Wushan Road, Guangzhou \\ 510640, P. R. China
}

Received 24 March 2009; accepted in revised form 17 May 2009

\begin{abstract}
Long chain semiaromatic polyamides were synthesized by the reactions of p-phenylenediacetic acid with long chain aliphatic diamines, and characterized by Fourier transform infrared spectroscopy (FTIR) and by proton nuclear magnetic resonance ( ${ }^{1} \mathrm{H}$ NMR). The thermal behaviors were determined by differential scanning calorimetry (DSC) and thermogravimetric analysis (TGA). The solubility, dynamic mechanical, physical and mechanical properties of the polyamides were also investigated. The resultant polyamides have intrinsic viscosity ranging from 1.8 to $2.1 \mathrm{dl} \cdot \mathrm{g}^{-1}$, their melting temperatures range from 254 to $290^{\circ} \mathrm{C}$, and their glass transition temperatures obtained from dynamic mechanical analysis are in the range $87-113^{\circ} \mathrm{C}$. The physical and mechanical properties of long chain semiaromatic polyamides were compared with those the PA9T. The results show that the heat resistance and the mechanical properties of poly(decamethylene-pphenylenediacetamide) (PA10P) are near to those of PA9T, so PA10P is a promising heat resistant engineering plastic.
\end{abstract}

Keywords: polymer synthesis, long chain diamine semiaromatic nylon

\section{Introduction}

Polyamides, also known as nylons, are a class of engineering thermoplastics that play an important role in modern industrial and commercial applications [1]. They can be economically produced by melt processing, but their poor dimensional stability and thermal properties impose limitations on successful applications in some industrial and other fields, especially in the surface mount technology (SMT) and the shell of automobile engine. For improving the heat resistance and strength of polyamides, aromatic rings were incorporated into the backbone of them [2-10]. According to these strategies, lots of aromatic and semiaromatic polyamides are commercially available, such as poly(p-phenylene terephthalamide) (PPTA) [11], Poly(m-phenyleneisophthalamide) (PMIA) [12], poly(hexamethyleneterephthalamide) (PA6T) [13], poly(hexamethyleneisophthalamide) (PA6I) [14, 15], poly(nonamethylene-terephthalamide) (PA9T) [16-19]. These aromatic and semiaromatic polyamides have been noted for their high thermal stability, chemical resistance, high strength, and high modulus as fibers. However, it is impossible to produce them except for PA9T by melting process due to their high glass transition and melting temperatures. So authors prepared aromatic and semiaromatic polyamides based on p-phenylenediacetic acid and 2,6-naphthalenedicarboxylic acid [20-22], however few people prepared long chain semiaromatic polyamides based on p-phenylenediacetic acid. These polyamides could have good physical and mechanical properties, good flow and low water-absorbance therefore, it is of great significance to synthesize novel long chain semiaromatic polyamides based on p-phenylenediacetic acid. 
We have synthesized semiaromatic polyamides based on p-phenylenediacetic acid and decanediamine [23]. In this contribution, we synthesized a series of novel semiaromatic polyamides: poly (decamethylene-p-phenylenediacetamide) (PA10P), poly(undecanediamine p-phenylenediacetic amides) (PA11P), poly(dodecanediamine p-phenylenediacetic amides) (PA12P) and poly(tridecanediamine p-phenylenediacetic amides) (PA13P) by using 1,10-decanediamine, 1,11-undecanediamine, 1,12dodecanediamine, 1,13-tridecanediamine and respectively. The long chain diamines are prepared from the corresponding long chain diacids by cyanating and aminating subsequently, which can be facilely obtained from light wax. The resultant polyamides were investigated by Fourier transform infrared spectrum (FTIR) and nuclear magnetic resonance ( ${ }^{1} \mathrm{H}$ NMR), thermal analysis, physical and mechanical properties, and dynamic mechanical analysis (DMA).

\section{Experimental}

\subsection{Materials}

p-Phenylenediacetic acid was purchased from Beijing Yanshan Lithification Chemical Co. Ltd (China) and 1,10-decanediamine, 1,11-undecanediamine, 1,12-dodecanediamine, 1,13-tridecanediamine were provided commercially by Zibo Guangtong Chemical Co. Ltd (China). They were purified by vacuum distillation before use.

\subsection{Synthesis}

PA10P was synthesized as follows (Figure 1). 1,10decanediamine $(258 \mathrm{~g}, 1.5 \mathrm{~mol})$ was dissolved in distilled water $(1000 \mathrm{ml})$ at $70^{\circ} \mathrm{C}$. Then the solution was added slowly into $500 \mathrm{ml}$ distilled water mixture of p-phenylenediacetic acid $(291.2 \mathrm{~g}, 1.5 \mathrm{~mol})$ with vigorous stirring and then stirred for $120 \mathrm{~min}$ at $85-95^{\circ} \mathrm{C}$. The white 1,10 -decanediamine-pphenylenediacetic acid salt (PA10P salt) precipitated from the solution was filtered over a Buchner funnel and then repeatedly washed with distilled water. After drying in a vacuum desiccator for $12 \mathrm{~h}$, the salt was obtained as a white powder $(476.6 \mathrm{~g}$, 94\%).

PA10P salt (476.6 g) was added into an autoclave and distilled water (400 g) was added to reduce volatilization of diamine during the polymerization. The autoclave was filled with carbon dioxide at room temperature and then heated to $220^{\circ} \mathrm{C}$ meanwhile the pressure up to $2.3 \mathrm{MPa}$. After $2 \mathrm{~h}$, the pressure of the autoclave was gradually decreased to atmospheric pressure in $2 \mathrm{~h}$ by deflating and the reaction temperature of the autoclave was increased to $240^{\circ} \mathrm{C}$. After reaction for another $2 \mathrm{~h}$, the prepolymer of PA10P was obtained (433.6 g, 91\%, intrinsic viscosity $[\eta]=1.3 \mathrm{dl} \cdot \mathrm{g}^{-1}$, $T_{m}=279^{\circ} \mathrm{C}$ ).

The prepolymer of PA10P was added into a solidstate polymerization kettle. Then, the kettle was evacuated to $10 \mathrm{~Pa}$ and the reaction temperature was increased to $220^{\circ} \mathrm{C}$. After $24 \mathrm{~h}$, the kettle was cooled to room temperature and the high molecular weight of PA10P was obtained $(412 \mathrm{~g}, 95 \%$, $[\eta]=2.1 \mathrm{dl} \cdot \mathrm{g}^{-1}, T_{m}=290^{\circ} \mathrm{C}$ ).

PA11P, PA12P and PA13P were prepared by the similar procedures with 1,11-undecanediamine, 1,12-dodecanediamine, and 1,13-tridecanediamine instead of 1,10-decanediamine, respectively.

\subsection{Characterization}

The polyamides were characterized by FTIR, ${ }^{1} \mathrm{H}$ NMR, intrinsic viscosity, DSC, DMA and TGA. The physical and mechanical properties were also investigated.

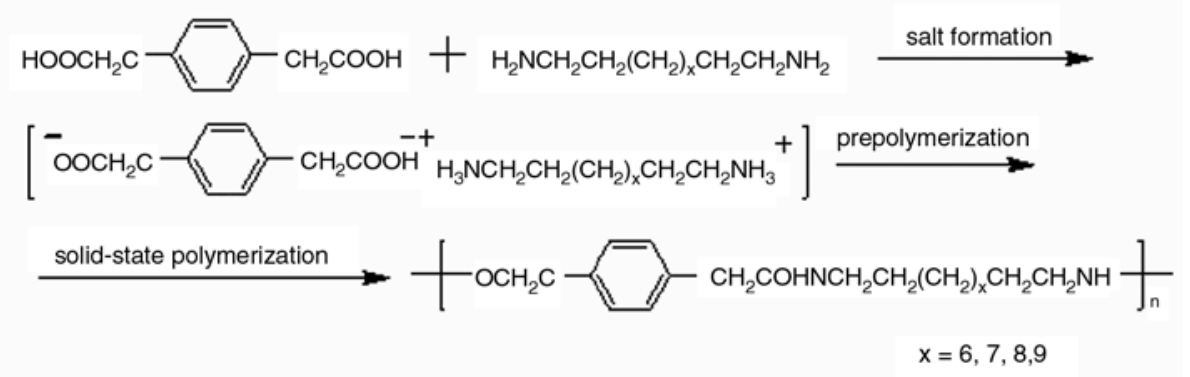

Figure 1. Synthesis routes of the obtained polyamides 
The intrinsic viscosities of the polyamides dissolved in concentrated sulfuric acid were determined in an Ubbelohde viscometer at $25 \pm 0.1^{\circ} \mathrm{C}$. The FTIR spectra were prepared by melting pressed-disc technique on a NICOLET 460 spectrometer. Proton nuclear magnetic resonance spectra were recorded with a Bruker DPX-400 (400 MHz), using deuterated trifluoroacetic acid as solvents and tetramethylsilane (TMS) as an internal reference.

DSC and TGA were carried out in a nitrogen stream using a NETSCH 204 calorimeter with a heating rate of $10^{\circ} \mathrm{C} \cdot \mathrm{min}^{-1}$. DMA was performed on a NETZSCH DMA-242 apparatus operating in tensile mode at a frequency of $2 \mathrm{~Hz}$ in the temperature ranged from -160 to $160^{\circ} \mathrm{C}$ with a heating rate of $3^{\circ} \mathrm{C} \cdot \mathrm{min}^{-1}$.

\section{Results and discussion}

\subsection{Syntheses of PA10P, PA11P, PA12P and PA13P}

A series of novel high molecular weights semiaromatic polyamides were synthesized by using pphenylenediacetic acid with long chain diamines. For improving the molecular weights of the polyamides, polyamide salts were prepared beforehand so as to maintain the accurately equal reaction ratio of the diacid and the diamine. It is worth noting that the solvent for the salt forming reaction is water, which is cheaper and environmental friendly compared with ethanol used in preparing other common polyamides. At the stages of the prepolymerization, high vapor pressure was applied to reduce the diamine loss. In the step of solid-state polycondensation, high vacuum was maintained, which is benefit for improving the molecular weights of the polyamides. The molecular weights of the polyamides were characterized by intrinsic viscosities, which are listed in Table 1.

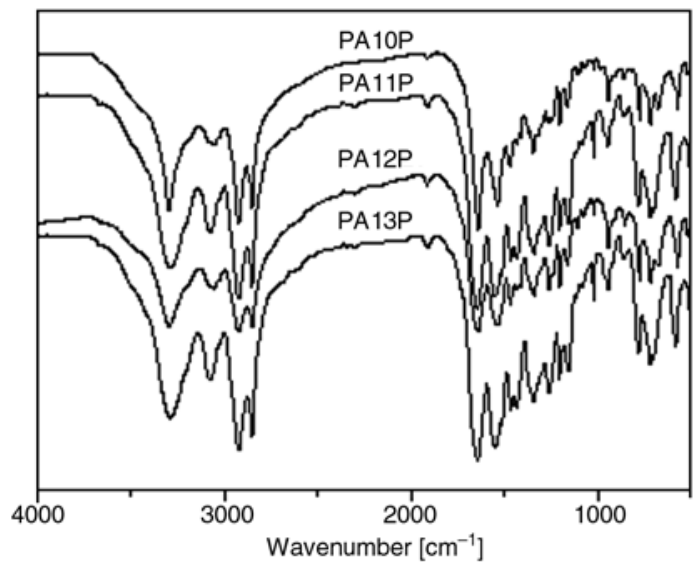

Figure 2. FT-IR spectra of the obtained polyamides

\subsection{Fourier transform infrared spectra}

FTIR spectra of the PA10P, PA11P, PA12P and PA13P are shown in Figure 2. All the characteristic absorptions of amide groups and methylene segments of polyamide are listed as following: $3301 \mathrm{~cm}^{-1}$ (hydrogen-bonded and $\mathrm{N}-\mathrm{H}$ stretching vibration), $2925 \mathrm{~cm}^{-1}$ (N-H in-plane bending vibration and $\mathrm{CH}_{2}$ vibration), $1647 \mathrm{~cm}^{-1}$ (amide $\mathrm{I}$, $\mathrm{C}=\mathrm{O}$ stretching vibration), $1539 \mathrm{~cm}^{-1}$ (amide II, $\mathrm{C}-\mathrm{N}$ stretching and $\mathrm{CO}-\mathrm{N}-\mathrm{H}$ bending vibration), $1020 \mathrm{~cm}^{-1}$ (amide IV, $\mathrm{C}-\mathrm{CO}$ stretching vibration), $795 \mathrm{~cm}^{-1}\left(\mathrm{CH}_{2}\right.$ wagging), $716 \mathrm{~cm}^{-1}$ (amide $\mathrm{V}, \mathrm{N}-\mathrm{H}$ out-of-plane bending vibration) and $846 \mathrm{~cm}^{-1}(\mathrm{CH}$ of phenylene vibration).

\subsection{Proton nuclear magnetic resonance}

Figure 3 presents the proton nuclear magnetic resonance spectra of the resultant polyamides in deuterated trifluoroacetic acid. The chemical shifts in the range at 7.2-7.4 ppm $(4 \mathrm{H})$ are attributed to the aromatic protons (position $a$ ). The chemical shifts at $3.9-4.1 \mathrm{ppm}(4 \mathrm{H})$ originate from the protons of methylene adjacent to aromatic ring at the position $b$ while that at $3.4-3.6 \mathrm{ppm}(4 \mathrm{H})$ come from

Table 1. The physical and mechanical properties of the obtained polyamides compared to PA9T

\begin{tabular}{|c|c|c|c|c|c|}
\hline & PA10P & PA11P & PA12P & PA13P & PA9T \\
\hline density $\left[\mathrm{g} \cdot \mathrm{cm}^{-3}\right]$ & 1.13 & 1.12 & 1.10 & 1.09 & 1.14 \\
\hline intrinsicviscosity $\left[\mathrm{dl} \cdot \mathrm{g}^{-1}\right]$ & 2.1 & 1.9 & 2.0 & 1.8 & - \\
\hline water absorption [\%] & 0.14 & 0.14 & 0.12 & 0.11 & 0.17 \\
\hline melting temperature $\left[\mathrm{C}^{\circ}\right]$ & 290 & 279 & 270 & 254 & 308 \\
\hline glass transition temperature $\left[{ }^{\circ} \mathrm{C}\right]$ & 113 & 102 & 96 & 87 & 126 \\
\hline tensile strength [MPa] & 89 & 86 & 85 & 81 & 92 \\
\hline breaking elongation [\%] & 42 & 47 & 52 & 63 & 20 \\
\hline bengding modulus [GPa] & 2.4 & 2.1 & 2.1 & 1.9 & 2.6 \\
\hline
\end{tabular}




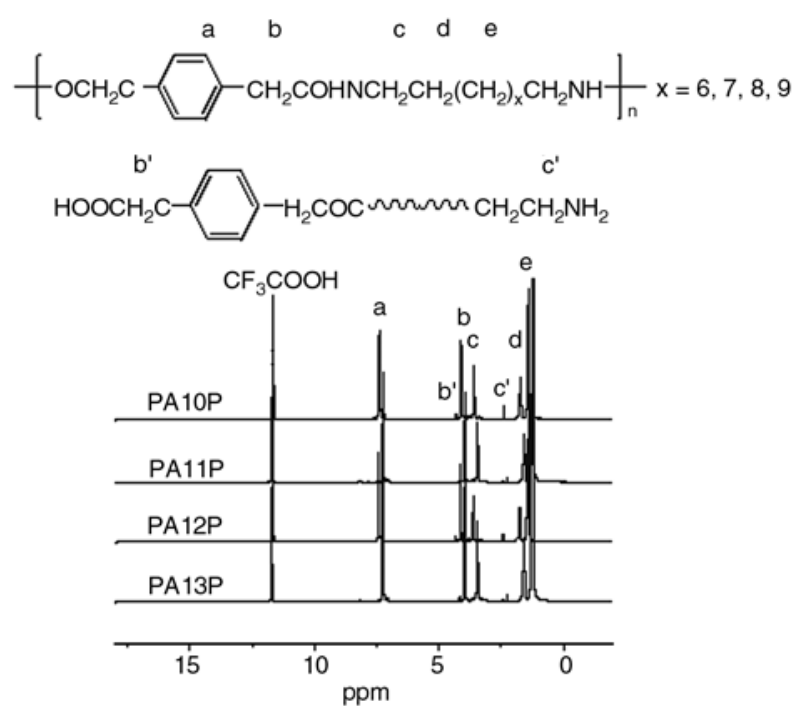

Figure 3. ${ }^{1} \mathrm{H}$ NMR spectra of the obtained polyamides

the protons of methylene adjacent to $\mathrm{NH}$ group at the position $c$. The peak at $1.6-1.7 \mathrm{ppm}(4 \mathrm{H})$ belong to protons at the position $d$. The peak at 1.6$1.7 \mathrm{ppm}$ belong to the other protons of the aliphatic chains (position $e$ ). The peak at $11.6 \mathrm{ppm}$ is attributed to trifluoroacetic acid.

The Chemical Shifts of the proton nuclear magnetic resonance and FTIR spectra of the resultant polyamides agree well with the theoretical values of the title compounds.

\subsection{Water absorption of the obtained polyamides}

The water absorptions of the obtained polyamides were measured according to ASTM D570 Standard, and the results are listed in Table 1. It can be seen the water absorption of the obtained polyamides decrease slowly with increasing the amount of methylene of polymer backbone, and all of them are lower than that of PA9T. The low water absorption is conducive to maintain dimensional and mechanical stability of products.

\subsection{Thermal behaviors}

Figure 4 depicts the DSC curves of the polyamides. The obtained polyamides exhibit double-melting endotherms, which is a common phenomenon observed in semicrystalline polymers [24-26]. Additionally, the melting temperatures $\left(T_{m}\right)$ of the polyamides decrease with increasing the amount of methylene of polymeric backbone. PA13P has the

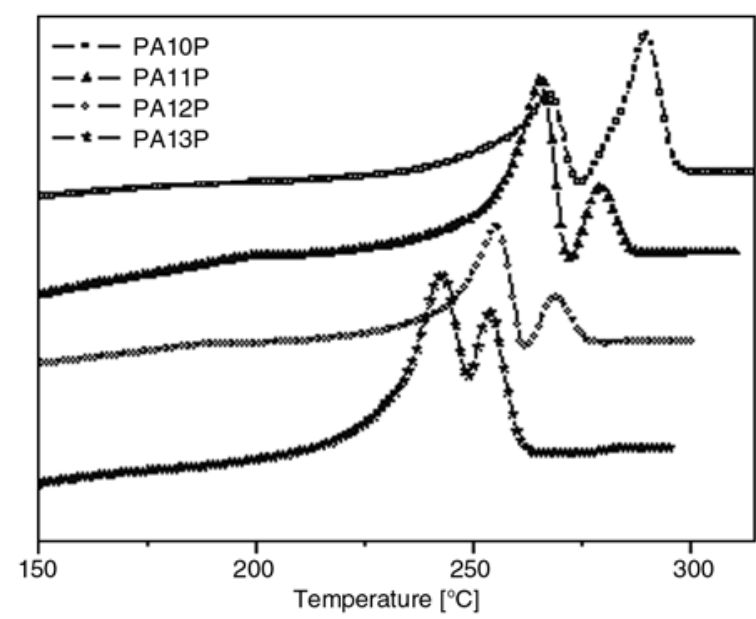

Figure 4. DSC curves of the obtained polyamides

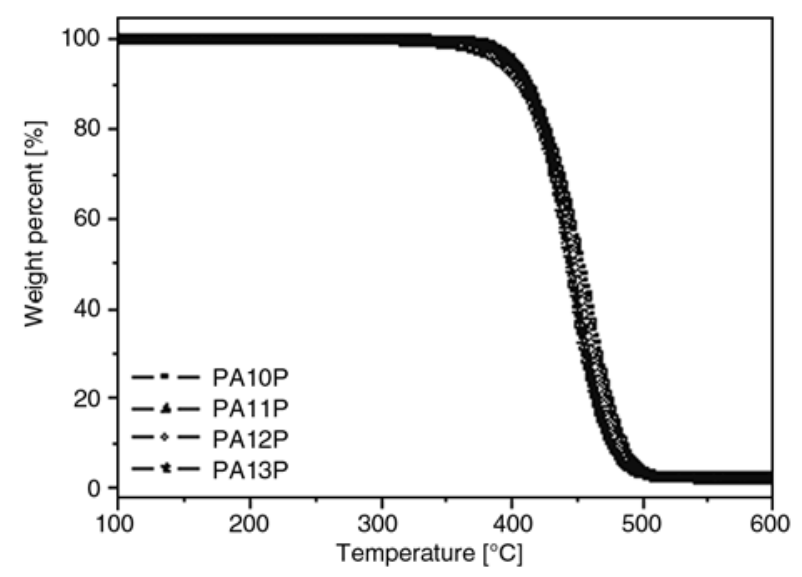

Figure 5. TG curves of the obtained polyamides

lowest melting point among the series of the resultant polyamides. $T_{m}$ of the PA10P, PA11P, PA12P and PA13P are $290,279,270$ and $254^{\circ} \mathrm{C}$.

TG curves of the resultant polyamides are shown in Figure 5. All the polyamides begin decomposition at $c a .426^{\circ} \mathrm{C}$, with the framework collapses temperatures $\left(T_{d}\right)$ at $c a .482^{\circ} \mathrm{C}$, which are higher than those of nylon 66 . The results suggest that the thermal stability of the polyamides has been improved by insetting phenylated linkage into the polymeric backbone.

\subsection{Dynamic mechanical analysis}

DMA was used to characterize the obtained polyamides and the curves are shown in Figure 6. Three obvious transition behaviors can be observed, and are defined as $\alpha, \beta$ and $\gamma$ relaxation, respectively. It is well known that the glass transition temperature $\left(T_{g}\right)$ of polyamide can be determined by $\alpha$ relaxation, since it is usually related to the segment 


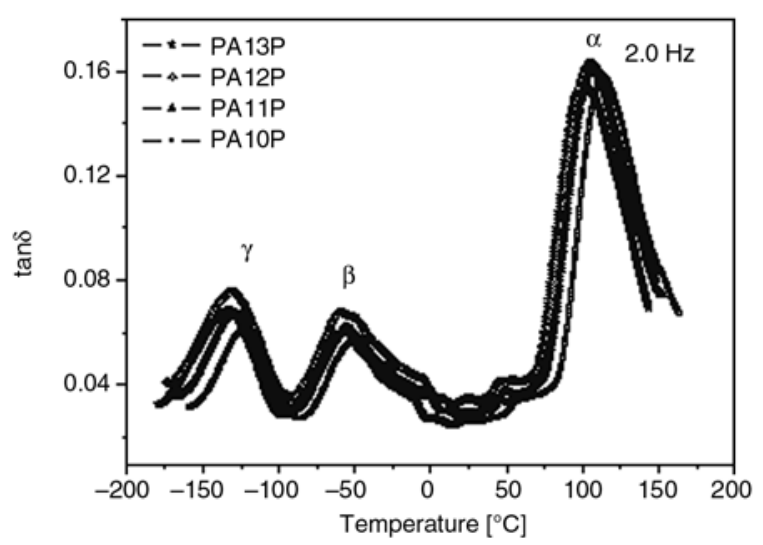

Figure 6. DMA curves of the obtained polyamides

movements in the noncrystalline area [27]. The $\beta$ relaxation reflects the mobility of carbonyl group of amorphous region, and the $\gamma$ relaxation reflects the co-moving of amido and methenes. The $\gamma$ relaxation also reflects the resultant polyamides exhibit fine low-temperature mechanical properties. The temperatures of $\alpha$ relaxation of the polyamides are $113.2,102.4,96.5$ and $87.1^{\circ} \mathrm{C}$, the temperatures of $\beta$ relaxation are $-48.9,-54.1,-56.2$ and $-60.2^{\circ} \mathrm{C}$, and the temperatures of $\gamma$ relaxation are -122.9 , $-126.6,-128.8$ and $-130.6^{\circ} \mathrm{C}$. The $\alpha, \beta$ and $\gamma$ relaxation temperatures decrease with increasing the amount of methylene of polymeric backbone.

\subsection{Mechanical properties}

Dry and standard specimens of the obtained polyamides by injection-moulding were prepared and their mechanical properties were measured according to ASTM D638 Standard. From Table 1, it can be observed the tensile strength and bending strength of PA10P are almost the same as that of PA9T at room temperature [28] and water absorption are lower than that of PA9T.

\subsection{The solubility of the resultant polyamides}

The solubility of the resultant polyamides was tested with different organic solvents which are shown in Table 2 . The sample $(100 \mathrm{mg})$ of the polyamides was added into test tube $(10 \mathrm{ml})$ containing appropriate solvent, and the solubility was observed. The resultant polyamides can easily dissolve in acidic solvents such as concentrated sulfu-
Table 2. The solubility of the obtained polyamides

\begin{tabular}{|l|c|c|c|c|}
\hline & PA10P & PA11P & PA12P & PA13P \\
\hline DMF & - & - & - & - \\
\hline NMP & - & - & - & - \\
\hline DMAc & - & - & - & - \\
\hline DMSO & - & - & - & - \\
\hline sulfuric acid & + & + & + & + \\
\hline m-Cresol & +- & +- & +- & +- \\
\hline pyridine & - & - & - & - \\
\hline chloroform & - & - & - & - \\
\hline tetrachloroethane & - & - & - & - \\
\hline chlorobenzene & - & - & - & - \\
\hline toluene & - & - & - & - \\
\hline methanol & - & - & - & - \\
\hline TFA & + & + & + & + \\
\hline
\end{tabular}

+ : soluble at room temperature, +- : partial soluble at room temperature, $-:$ not soluble at room temperature

ric acid and trifluoroacetic acid (TFA) at room temperature, while they are insoluble in dimethylsulphoxide (DMSO), N, $\mathrm{N}^{\prime}$-dimethylformamide (DMF), 1-methyl-2-pyrrolidenone (NMP), dimethylacetamide (DMAc), m-cresol, tetrahydrofuran (THF), and chloroform. The result shows that the resultant polyamides exhibit good chemical solvents resistance.

\section{Conclusions}

A series of novel high molecular weights semaiaromatic polyamides including PA10P, PA11P, PA12P and PA13P were synthesized by using $\mathrm{p}$ phenylenediacetic acid with 1,10-decanediamine, 1,11-undecanediamine, 1,12-dodecanediamine and 1,13-tridecanediamine, respectively. FTIR and proton nuclear magnetic resonance spectra confirmed the chemical structure of the prepared polyamides. The thermal, mechanical properties and dynamic mechanical properties were studied. Among the long chain polyamides, the mechanical properties of PA10P achieved the best performance, which are almost the same as those of PA9T. It's worth noting that PA10T can be prepared from convenient raw materials using the environmental friendly solvents (water). Compared to PA9T, the low water absorption and good flexibility of PA10P demonstrates it could be a promising, heat resistant and processable engineering plastic and its applications in wide fields could be desired. 


\section{References}

[1] Levchik S. V., Weil E. D., Lewin M.: Thermal decomposition of aliphatic nylons. Polymer International, 48, 532-533 (1999).

DOI: 10.1002/(SICI)1097-0126(199907)48:7<532::

\section{AID-PI214>3.0.CO;2-R}

[2] Kudo K., Suguie J., Hirami M.: Melt-polymerized aliphthatic-aromatic copolyamides I. Melting points of nylon 66 copolymerized with aromatic diamines and terephthalic acid. Journal of Applied Polymer Science, 44, 1625-1629 (1992).

DOI: $10.1002 /$ app.1992.070440916

[3] Liu Y., Donovan J. A.: Miscibility and crystallization of semicrystalline nylon 6 and amorphous nylon 6IcoT blends. Polymer, 36, 4797-4803 (1995). DOI: 10.1016/0032-3861(95)99295-6

[4] Zhang G. Z., Yoshida H., Kawai T.: Miscibility of Nylon 66 and Nylon 48 blend evaluated by crystallization dynamics. Thermochimica Acta, 416, 79-85 (2004).

DOI: $\underline{10.1016 / \text { j.tca.2003.01.002 }}$

[5] Khanna Y. P., Murthy N. S., Kuhn W. P., Day E. D.: Pseudo super-miscibility: Blends of semi-crystalline nylon pairs exhibiting a single $T_{g}$ and a single $T_{m}$. Polymer Engineering and Science, 39, 2222-2232 (1999). DOI: $10.1002 /$ pen. 11610

[6] Brisson J., Breault B.: Miscibility of polyamide blends. 1. Molecular modeling of poly(n-methyleneisophthalamide)-poly(meta-phenyleneisophthalamide) blends. Macromolecules, 24, 495-504 (1991). DOI: $\underline{10.1021 / \mathrm{ma} 00002 \mathrm{a} 024}$

[7] Persyn O., Miri V., Lefebvre J-M., Ferreiro V., Brink T., Stroeks A.: Mechanical behavior of films of miscible polyamide 6/polyamide 6I-6T blends. Journal of Polymer Science Part B: Polymer Physics, 44, 16901701 (2006). DOI: $10.1002 /$ polb.20825

[8] Shibayama M., Uenoyama K., Oura J-I., Nomura S., Iwamoto T.: Miscibility and crystallinity control of nylon 6 and poly(m-xylene adipamide) blends. Polymer, 36, 4811-4816 (1995).

DOI: 10.1016/0032-3861(95)99297-8

[9] Endo M., Morishima Y., Yano S.,Tadano K., Murata Y., Tsunashima K.: Miscibility in binary blends of aromatic and alicyclic polyamides. Journal of Applied Polymer Science, 101, 3971-3978 (2006). DOI: 10.1002/app.22912

[10] Ellis T. S.: Aromatic polyamide blends: Enthalpy relaxation and its correlation with phase phenomena. Macromolecules, 23, 1494-1503 (1990). DOI: $10.1021 / \mathrm{ma} 00207 \mathrm{a} 042$

[11] Rao Y., Waddon A. J., Farris R. J.: Structure-property relation in poly ( $p$-phenylene terephthalamide) (PPTA) fibers. Polymer, 42, 5937-5940 (2001). DOI: $\underline{10.1016 / \mathrm{S} 0032-3861(00) 00905-8}$
[12] Ferreiro J. J., de la Campa J. G., Lozano A. E., de Abajo J.: Polyisophthalamides with heteroaromatic pendent rings: Synthesis, physical properties, and water uptake. Journal of Polymer Science Part A: Polymer Chemistry, 43, 5300-5311 (2005). DOI: $10.1002 /$ pola. 21000

[13] Ballistreri A., Garozzo D., Giuffrida M., Maravigna P.: Thermal decomposition processes in aliphatic-aromatic polyamides investigated by mass spectrometry. Macromolecules, 19, 2693-2699 (1986).

DOI: $10.1021 / \mathrm{ma} 00165 \mathrm{a} 005$

[14] Siciliano A., Severgnini D., Seves A., Pedrelli T., Vicini L.: Thermal and mechanical behavior of polyamide 6/polyamide $6 \mathrm{I} / 6 \mathrm{~T}$ blends. Journal of Applied Polymer Science, 60, 1757-1764 (1996).

DOI: $10.1002 /($ SICI $) 1097-4628(19960606) 60: 10$ $\leq 1757::$ AID-APP29>3.0.CO;2-\#

[15] Eersels K. L., Groeninckx G.: Influence of interchange reactions on the crystallization and melting behaviour of polyamide blends as affected by the processing conditions. Polymer, 37, 983-984 (1996). DOI: 10.1016/0032-3861(96)87281-8

[16] Uddin A. J., Ohkoshi Y., Gotoh Y., Nagura M., Hara T.: Influence of moisture on the viscoelastic relaxations in long aliphatic chain contained semiaromatic polyamide, (PA9-T) fiber. Journal of Polymer Science Part B: Polymer Physics, 41, 2878-2891(2003). DOI: $10.1002 /$ polb.10602

[17] Uddin A. J., Ohkoshi Y., Gotoh Y., Nagura M., Hara T.: Melt spinning and laser-heated drawing of a new semiaromatic polyamide, PA9-T fiber. Journal of Polymer Science Part B: Polymer Physics, 42, 433 444 (2004).

DOI: $10.1002 /$ polb. 10710

[18] Uddin A. J., Gotoh Y., Ohkoshi Y., Nagura M., Endo R., Hara T.: Hydration in a new semiaromatic polyamide observed by humidity-controlled dynamic viscoelastometry and X-ray diffraction. Journal of Polymer Science Part B: Polymer Physics, 43, 16401648 (2005).

DOI: $\underline{10.1002 / \text { polb.20446 }}$

[19] Uddin A. J., Ohkoshi Y., Gotoh Y., Nagura M., Endo R., Hara T.: Effects of take-up speed of melt spinning on the structure and mechanical properties of maximally laser drawn PA9-T fibers. International Polymer Processing, 21, 263-271 (2006).

[20] Ridgway J. S.: Structure-property relationships of ring-containing nylon 66 copolyamides. Journal of Polymer Science Part A-1: Polymer Chemistry, 8, 3089-3111 (1970).

DOI: $\underline{10.1002 / \text { pol.1970.150081105 }}$

[21] Scandola M., Pizzoli M., Drusiani A., Garbuglio C.: Dynamic mechanical properties and melting pointis of some aliphatic and partially aromtic polyamides. European Polymer Journal, 10, 101-107 (1974). DOI: $\underline{10.1016 / 0014-3057(74) 90058-5}$ 
[22] Yang S. H., Liu M. Y., Wang Y. D., Fu P., Chen Z. Y., Zhang Y. C., Zhao Q. X.: Synthesis and characterization of PA12N (in Chinese). Material Science and Technology, 16, 117-119 (2008).

[23] Wang W. Z., Liu B. Y., Li R. X., Zhang Y. H.: Synthesis and physical mechanical properties of poly (decanediamine p-phenylenedacetic amide). Polymer Materials: Science and Engineering, 25, 144-146 (2009).

[24] Li Y. J., Zhu X. Y., Tian G. H., Yan D. Y., Zhou E.: Multiple melting endotherms in melt-crystallized nylon 10,12. Polymer International, 50, 677-678 (2001).

DOI: $10.1002 /$ pi.682
[25] Ramesh C., Keller A., Eltink S. J.: Studies on the crystallization and melting of nylon 66:3. Melting behaviour of negative spherulites by calorimetry. Polymer, 35, 5300-5302 (1994).

DOI: 10.1016/0032-3861(94)90483-9

[26] Hybart F. J., Platt J. D.: The melting of 66 nylon: Observations by differential thermal analysis. Journal of Applied Polymer Science, 11, 1449-1453 (1967). DOI: 10.1002/app.1967.070110808

[27] Li W. H., Yan D. Y.: Synthesis and characterization of nylons based on hexadecane diacid. Journal of Applied Polymer Science, 88, 2462-2467 (2003). DOI: 10.1002/app.12048

[28] Ma J. M., Song S. W., Guo J.: New heat resistance polyamide. Modern Plastics Processing and Applications, 15, 41-44 (2003). 